\title{
The relationships between washing parameters, fabric movement and wrinkling in a top-loading washer
}

DOI:

$10.1177 / 0040517517700197$

\section{Document Version}

Accepted author manuscript

Link to publication record in Manchester Research Explorer

\section{Citation for published version (APA):}

Gong, R., Wei, Y., Ning, L., \& Ding, X. (2017). The relationships between washing parameters, fabric movement and wrinkling in a top-loading washer. Textile Research Journal. https://doi.org/10.1177/0040517517700197

\section{Published in:}

Textile Research Journal

\section{Citing this paper}

Please note that where the full-text provided on Manchester Research Explorer is the Author Accepted Manuscript or Proof version this may differ from the final Published version. If citing, it is advised that you check and use the publisher's definitive version.

\section{General rights}

Copyright and moral rights for the publications made accessible in the Research Explorer are retained by the authors and/or other copyright owners and it is a condition of accessing publications that users recognise and abide by the legal requirements associated with these rights.

\section{Takedown policy}

If you believe that this document breaches copyright please refer to the University of Manchester's Takedown Procedures [http://man.ac.uk/04Y6Bo] or contact uml.scholarlycommunications@manchester.ac.uk providing relevant details, so we can investigate your claim.

\section{OPEN ACCESS}




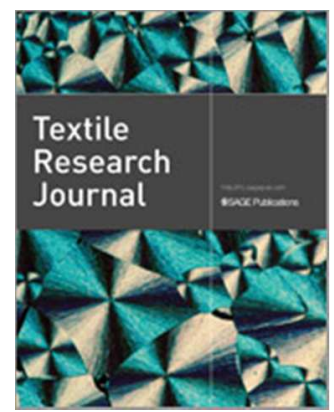

\section{The relationships between washing parameters, fabric movement and wrinkling in a top-loading washer}

\begin{tabular}{|c|l|}
\hline Journal: & Textile Research Journal \\
\hline Manuscript ID & TRJ-16-0576.R3 \\
\hline Manuscript Type: & Original Manuscript \\
\hline Keywords: & $\begin{array}{l}\text { textile care/wrinkling < management of: < Systems, Product and Systems } \\
\text { Engineering, properties < Materials, performance < Materials, textile } \\
\text { motion, top-loading washer, washing machine parameters }\end{array}$ \\
\hline Abstract: & $\begin{array}{l}\text { Easy care for clothing is increasingly important, but the major problem is } \\
\text { still the severe wrinkles formed on garments after machine washing. In this } \\
\text { research, orthogonal tests and the analysis of variance (ANOVA) at a 95\% } \\
\text { confidence level were used to determine the critical parameters that affect } \\
\text { fabric smoothness. We developed a video capturing and processing system } \\
\text { for dynamic measurements of fabric in a top-loading washer to find the } \\
\text { relationship between fabric movement and wrinkling performance during } \\
\text { laundering. The ANOVA results showed that the smoothness of woven } \\
\text { cotton fabrics was mainly affected by the washing load and the drum } \\
\text { rotating speed, with a p value 0.000 and 0.036 respectively. Additionally, } \\
\text { relation models for fabric movements suggested by a curvilinear regression } \\
\text { analysis indicated that the main causes of fabric wrinkling during top- } \\
\text { loading washing were liquor ratio and the centrifugal force imposed on the } \\
\text { fabric. The smoothness grade increased with the decrease of washing load } \\
\text { and drum rotating speed since these settings led to lower liquor ratio with } \\
\text { a constant water volume and less stress on the fabric. The results of this } \\
\text { study provide valuable information for the optimization of washing } \\
\text { programs for fabric smoothness. }\end{array}$ \\
\hline \hline
\end{tabular}

\section{SCHOLARONE ${ }^{\text {th }}$}

Manuscripts 


\title{
The relationships between washing parameters, fabric movement
} and wrinkling in a top-loading washer

\begin{abstract}
Easy care for clothing is increasingly important, but the major problem is still the severe wrinkles formed on garments after machine washing. In this research, orthogonal tests and the analysis of variance (ANOVA) at a 95\% confidence level were used to determine the critical parameters that affect fabric smoothness. We developed a video capturing and processing system for dynamic measurements of fabric in a top-loading washer to find the relationship between fabric movement and wrinkling performance during laundering. The ANOVA results showed that the smoothness of woven cotton fabrics was mainly affected by the washing load and the drum rotating speed, with a $\mathrm{p}$ value 0.000 and 0.036 respectively. Additionally, relation models for fabric movements suggested by a curvilinear regression analysis indicated that the main causes of fabric wrinkling during top-loading washing were liquor ratio and the centrifugal force imposed on the fabric. The smoothness grade increased with the decrease of washing load and drum rotating speed since these settings led to lower liquor ratio with a constant water volume and less stress on the fabric. The results of this study provide valuable information for the optimization of washing programs for fabric smoothness.
\end{abstract}

Keywords: Top-loading washer, washing machine parameters, fabric movements, wrinkling 


\section{Background}

Top-loading washing machines are known for their high washing performance and have claimed the maximum market share in Asia. However, they have a very high tendency to wrinkle textiles during laundering, especially those made of cotton fabrics ${ }^{1-3}$. The mechanical actions by the centrifugal force of a drum bath and the hydrodynamic flow make the fabrics rotate, bend and rub against each other, and these mechanical actions are important factors that contribute to wrinkling. However, earlier studies have focused more on the roles of fabric properties and washing parameters on washing performance, little on the role of fabric movement on wrinkling performance. Previous research on fabric movement in washing machines included the movements in a front-loading washer ${ }^{4,5}$. Few studies are available on the mechanism of wrinkling in a top-loading washing machine.

Among the previous studies on the roles of washing parameters and their relationship to the wrinkling performance, L. Higgins et al. ${ }^{4}$ studied the effects of detergent, fabric softener and fabric structure on the wrinkling of woven cotton fabrics, and they found that the effects were minimal. In recent years, with consumers' increasing need for easy care, researchers have gradually focused on the optimization of washing programs. Ikilem Gocek et al. ${ }^{6}$ have improved the wrinkling behavior of linen fabrics during washing by selecting suitable levels of temperature, rate of mechanical action, revolution per minute and water amount applied during laundering. Additionally, Shao and Yuan ${ }^{7-9}$ have optimized washing programs for cotton shirts by regulating washing parameters, including washing temperature, drying time, rotating speed and so on. Another noteworthy observation from Yuan's study is that a fabric's thickness has an obvious impact on the smoothness of woven cotton fabrics in a front-loading washer. These studies indicate that the washing parameters such as temperature, water amount, rotating speed, spinning time and fabric thickness are likely to influence the wrinkling of fabrics during laundering. However, the mechanism of the wrinkling process is still not clear.

Among a few studies that have investigated the fabric movements in a front-loading washer ${ }^{4}$, ${ }^{5,10-12}$, Park and Yun ${ }^{5,11,13}$ have analyzed the types of fabric movements inside a front-loading washer to examine the effects of the fabric properties on fabric movement and washing performance. They used high-speed cameras to record and track the fabrics' outlines. Later, Wang 
Lei et al. ${ }^{14}$ developed a video capturing and processing system for dynamic measurements of a fabric's wrinkle recovery angle, inspired by the advantages of video sequence in dynamic measurement.

In this study, we identified the significant washing parameters that influenced fabric smoothness using the orthogonal experimental design and ANOVA tests. We analyzed fabric movements to explain the relationship between the major parameters and wrinkling through video sequencing. Also, we established regression models to quantify the relationship between a fabric's smoothness and its movements.

\section{Experimental details}

\section{Design of experiment}

Orthogonal design

In this investigation, the major parameters that affect fabric smoothness after washing in a top-loading washer needed to be determined first. The orthogonal design of four factors at three levels was applied and four key influencing factors-rotating speed, washing load size, spinning time and fabric thickness were identified in the literature ${ }^{6,8,15}$. Water temperature was excluded since top-loading washing machines in China always operate at room temperature because there is only one cold water system. The levels of corresponding factors were set according to the adjustable range of the washing machine. The detailed orthogonal design is shown in Table 1, and each test was repeated five times to improve accuracy.

Table 1. Orthogonal design

\begin{tabular}{ccccc}
\hline Test & $\begin{array}{c}\text { Washing load size } \\
(\mathrm{kg})\end{array}$ & $\begin{array}{c}\text { Rotating speed }^{\mathrm{b}} \\
(\mathrm{rpm})\end{array}$ & $\begin{array}{c}\text { Spinning time } \\
(\mathrm{min})\end{array}$ & Thickness $^{\mathrm{a}}$ \\
\hline 1 & 1 & 389 & 3 & Thin \\
2 & 1 & 907 & 7 & Medium thick \\
3 & 1 & 648 & 5 & Thick \\
4 & 2 & 648 & 3 & Medium thick \\
5 & 2 & 389 & 7 & Thick \\
6 & 2 & 907 & 5 & Thin \\
\hline
\end{tabular}




\begin{tabular}{llllc}
\hline 7 & 3 & 648 & 7 & Thin \\
8 & 3 & 389 & 5 & Medium thick \\
9 & 3 & 907 & 3 & Thick \\
\hline
\end{tabular}

Note: a. Thin $<0.25 \mathrm{~mm}$, Medium thick: $0.25-0.40 \mathrm{~mm}$, Thick $>0.40 \mathrm{~mm}$

b. Rotating speed consists of washing speed and spinning speed.

\section{Single factor experimental design}

After determining the major influencing factors — washing load size and rotating speed for fabric wrinkling in the top-loading washer, we studied and analyzed the relationships between washing load size/rotating speed, fabric movement and wrinkling. The main washing parameters of single factor experimental design washing load size and rotating speed are shown in Table 2 and Table 3 respectively.

Table 2. Standard washing procedure

\begin{tabular}{cccccccc}
\hline Temperature & Washing & Water & Washing & Rinsing & Rinsing & Spinning & Rotating \\
$(\square)$ & load size & level & time & times & Time & time & speed \\
& $(\mathrm{kg})$ & $(\mathrm{L})$ & $(\mathrm{min})$ & & $(\mathrm{min})$ & $(\mathrm{min})$ & $(\mathrm{rpm})$ \\
\hline 29 & $1 / 2 / 3 / 3.5 / 4$ & 48 & 15 & 2 & 3 & 5 & 389 \\
\hline
\end{tabular}

Table 3. Washing procedures with different rotating speeds

\begin{tabular}{cccccc}
\hline $\begin{array}{c}\text { Temperature } \\
\left({ }^{\circ} \mathrm{C}\right)\end{array}$ & Rotating speed & Water & Washing & Rinsing & Spinning \\
& $(\mathrm{rpm})$ & level & time & times & $\begin{array}{c}\text { time } \\
(\mathrm{min})\end{array}$ \\
\hline 30 & $259 / 389 / 518 / 648 / 777 / 907 / 1036$ & 48 & 15 & 2 & 5 \\
\hline
\end{tabular}

\section{Facilities and equipment}

\section{Video capturing and processing system}

Inspired by the advantages of video sequencing in dynamic measurements, we developed a video capturing and processing system for the dynamic measurements of fabric movement in a top-loading washer (See Figure 1). 


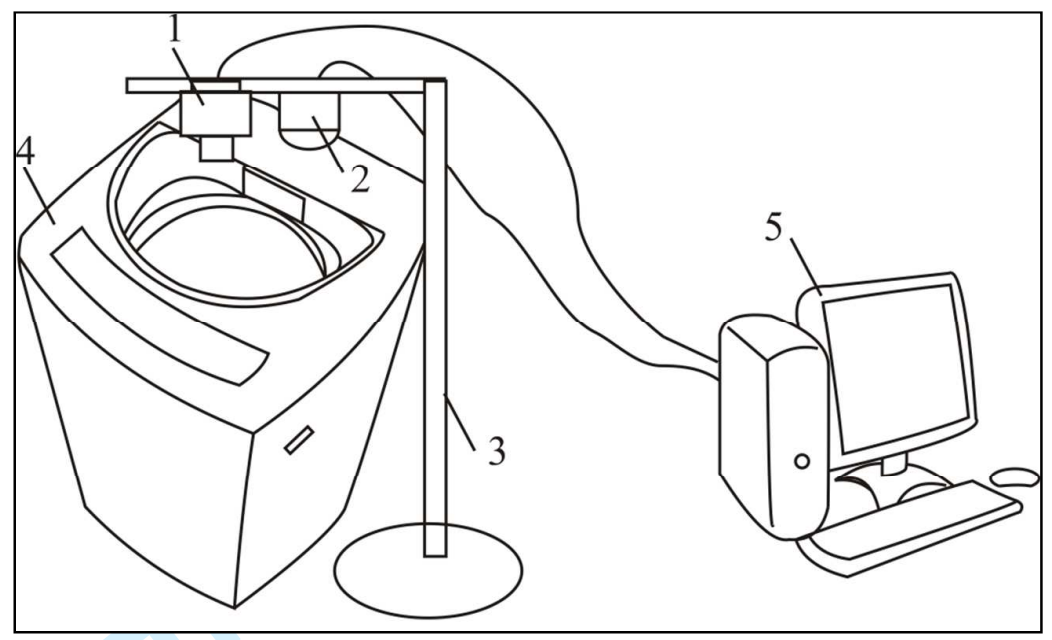

Figure1. The video capturing and processing system

Note: The system consists of two major parts, a video sequencing acquisition part and an image processing part. The components in Figure 1 are (1) SONY DSC-W290 camera, (2) light source, (3) adjustable support leg, (4) top-loading washer (XQS70-ZY1128, Haier Co. Ltd.) and (5) computer.

The camera and light source were used to capture fabric washing movements in the top-loading washer. The videos were taken and processed by the Corel Video Studio Pro. X5 and CorelDraw 12.0 installed in the computer. The adjustable support leg was used to move the camera and light source to the best position for recording a video. Each fabric movement was analyzed for three seconds (the minimum washing period), and 21 frames were tracked for each three seconds.

The procedure of video frame processing is shown in Figure 2. First, the fabric washing movement was recorded for the minimum washing period ( 3 seconds). Then the video was decomposed to 21 frames to track the outline of the fabric in each frame. Finally, all of the outlines in one washing period were added together to create the fabric's movement image. The video of the fabric washing was converted by means of the outlines and the fabric's center of gravity and in order to analyze the fabric's movements. 


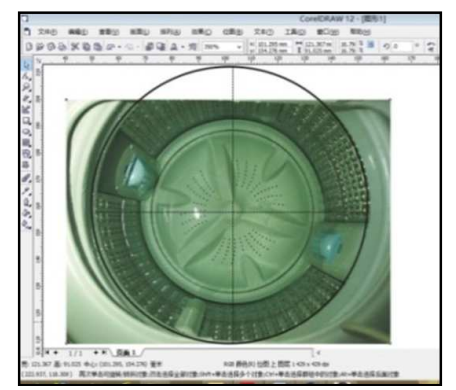

(a) identification of the washing region

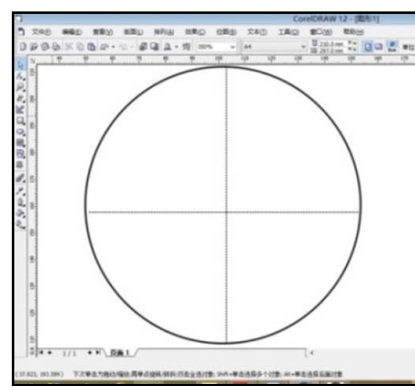

(b) washing region

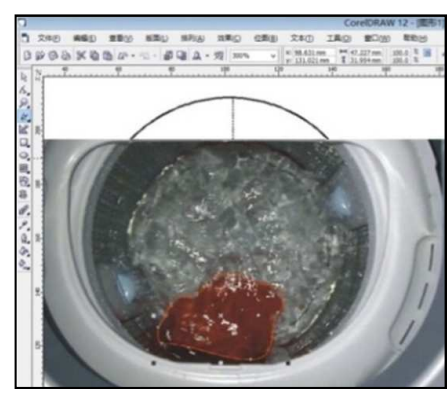

(c) an outline

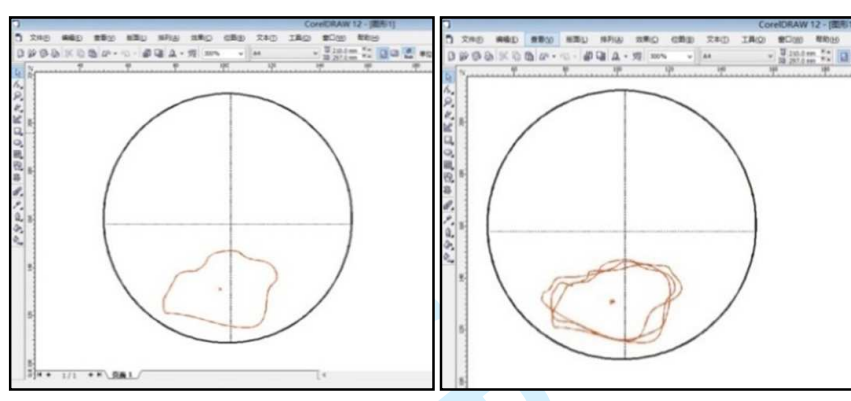

(d) fabric center of gravity

(e) pattern overlay

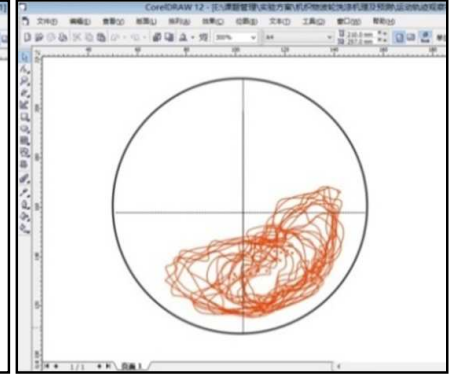

(f) movement

Figure 2. Image processing of fabric washing movement

\section{Washer}

The laundering procedure was completed using a top-loading, automatic washing machine with washing capacity 7.5 Kg made by Haier (Haier XQS70-ZY1128, Qingdao Haier Co. Ltd.) based on ISO6330:2012.

\section{Power measurement}

A power measuring meter (CLM221, Christ-elektronik) was used to measure the electric energy consumption for each washing cycle. This is the energy source of the fabric movement based on the law of conservation of energy.

\section{Materials}

The fabric samples used in this study were prepared from commercially available fabrics, and the characteristics of the samples for the orthogonal design are presented in Table 4. For the single experimental design, specimen C6 was selected as the test sample to study the relationship 
between washing parameters, fabric movement and wrinkling. The selected samples were all woven, $100 \%$ cotton without wrinkle-resistant finishing since woven cotton fabrics are widely used but wrinkle easily. According to AATCC $124: 2010$, samples were cut into $38 \mathrm{~cm} \times 38 \mathrm{~cm}$ in dimensions. Ballasts of $100 \%$ plain, woven cotton fabric $(92 \mathrm{~cm} \times 92 \mathrm{~cm} /$ piece $)$ and $100 \%$ knitted polyester textile $(20 \mathrm{~cm} \times 20 \mathrm{~cm} /$ piece $)$ were added to the specimens under testing at the ratio of 7:3 in order to achieve the designed washing loads. All samples were used after conditioning at $20^{\circ} \mathrm{C}$ and $60 \mathrm{RH} \%$ for at least 24 hours.

The detergent used in the experiments conforms to the requirements of International Electrotechnical Commission (IEC) standard, IEC $60456^{16}$. The composition of the detergent were $77 \%$ base powder with enzyme and foam inhibitor, $20 \%$ sodium perborate tetrahydrate and $3 \%$ bleach activator tetra-acetylethylenediamine (TAED).

Table 4. Characteristics of the cotton specimen

\begin{tabular}{cccc}
\hline Code & Wave & Thickness & $\begin{array}{c}\text { Weight } \\
\mathrm{g} / \mathrm{m}^{2}\end{array}$ \\
\hline C1 & twill & 0.20 & 68.0 \\
C2 & plain & 0.23 & 91.5 \\
C3 & plain & 0.24 & 104.9 \\
C4 & plain & 0.27 & 94.4 \\
C5 & plain & 0.30 & 84.2 \\
C6 & plain & 0.31 & 139.6 \\
C7 & weft rib & 0.38 & 133.6 \\
C8 & plain & 0.40 & 105.9 \\
C9 & twill & 0.43 & 155.7 \\
C10 & weft rib & 0.46 & 170.4 \\
C11 & weft rib & 0.59 & 241.1 \\
C12 & twill & 0.65 & 211.6 \\
C13 & satin & 0.67 & 255.2 \\
\hline
\end{tabular}

\section{Evaluation of smoothness}

All specimens were line-dried under standard atmospheric conditions for 4 to 24 hours. And 
the smoothness of the specimens was evaluated based on AATCC 124:2010 ${ }^{17}$ in a standardized inspection booth.

\section{Statistical analysis}

IBM SPSS Statistics 19.0 (Predictive Analytics Software, IBM, USA) was applied to analyze the relationship between the washing parameters, fabric movements and fabric wrinkling performance. Statistically significant washing parameters were determined by the analysis of variance (ANOVA). Curvilinear regression analysis was also used to derive the relationship models between movement indexes and smoothness appearance.

\section{Results and discussions}

\section{Effects of washing machine parameters on the fabric's smoothness}

\section{appearance}

The grades of the fabric's smoothness (SA) after washing are illustrated in Table 5. From the smoothness grade, the washing load has a negative influence on fabric wrinkling after washing in a top-loading washer. When the washing load is $1 \mathrm{~kg}$, the smoothness grades are higher than the grades of the other two washing loads. When increasing rotating speed from $389 \mathrm{rpm}$ to $907 \mathrm{rpm}$, the smoothness tends to decrease. Faster washing speed increases the number of wrinkling because of relative motion of fabrics and fluid, while the increase of spinning speed deepens the wrinkling as a result of centrifugal force imposed on the fabrics. However, with prolonged spinning time, the grade of SA varies slightly which indicated that the spinning time had a minor influence on wrinkling performance. The thickness, which was expected to affect the wrinkling, is not significant in influencing the smoothness within these experimental conditions. The fabric parameters excluding fiber component do not seem to be major factors under the coaction of washing machine parameters in a top-loading washer under the given conditions. 
Table 5. Results of orthogonal test

\begin{tabular}{ccccccc}
\hline Test & $\begin{array}{c}\text { Washing load } \\
\text { size }\end{array}$ & $\begin{array}{c}\text { Rotating } \\
\text { speed } \\
(\mathrm{kg})\end{array}$ & $\begin{array}{c}\text { Spinning time } \\
(\mathrm{rpm})\end{array}$ & $\begin{array}{c}\text { Thickness } \\
(\mathrm{min})\end{array}$ & $\begin{array}{c}\text { Smoothness } \\
\text { appearance } \\
(\text { grade })\end{array}$ & $\begin{array}{c}\text { Standard } \\
\text { deviation. }\end{array}$ \\
\hline 1 & 1 & 389 & 3 & Thin & 2.7 & 0.2 \\
2 & 1 & 907 & 7 & Medium thick & 2.3 & 0.0 \\
3 & 1 & 648 & 5 & Thick & 2.5 & 0.1 \\
4 & 2 & 648 & 3 & Medium thick & 2.2 & 0.2 \\
5 & 2 & 389 & 7 & Thick & 2.3 & 0.0 \\
6 & 2 & 907 & 5 & Thin & 2.0 & 0.3 \\
7 & 3 & 648 & 7 & Thin & 1.8 & 0.4 \\
8 & 3 & 389 & 5 & Medium thick & 2.1 & 0.1 \\
9 & 3 & 907 & 3 & Thick & 1.8 & 0.2 \\
\hline
\end{tabular}

In order to study the relationships between the washing parameters and fabric wrinkling, the factors that are significant in affecting the fabric smoothness appearance are determined by ANOVA. From the ANOVA test, washing load and rotating speed are found significant in differentiating the smoothness appearance at a $95 \%$ confidence level $(\mathrm{p}<0.05)$.

After determining the significant factors, we investigated the fabric movement to study the relationships between washing parameters and fabric wrinkling.

\section{Analysis of fabric movements during washing}

Top-loading washing is a complex multi-phase and multi-scale process, coupled with three-dimensional motions of the fluid and cloth, large and complex cloth deformation, cloth permeability, and the unsteadiness of fluid motion. Although two-dimensional observation cannot capture the vertical tumbling motion of the cloth pieces in a vertical-axis washing machine, it is recognized to be highly correlated with the effectiveness of the washing processes ${ }^{18}$.

\section{The relationship between washing load, fabric movement and wrinkling}


In order to analyze the washing load influence on wrinkling, we analyzed the movements of one piece, two-piece, and three-piece specimens (Figure 3). All washing procedures were common and kept as much the same as possible apart from the variable parameters such as rotating speed and washing load. The washing programs are shown in Table 2 .
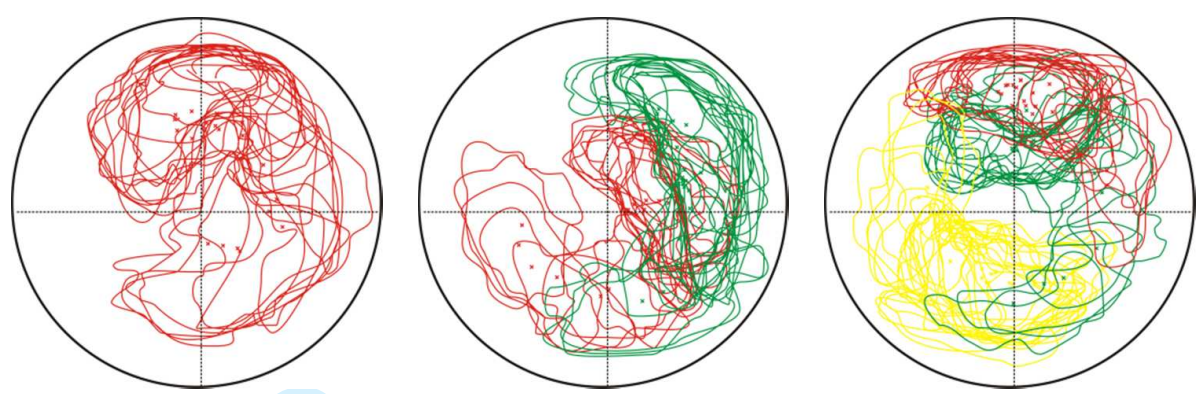

(a) 1-piece specimen, 389rpm;

(b) 2-piece specimen, 389rpm;

(c) 3-piece specimen, 389rpm
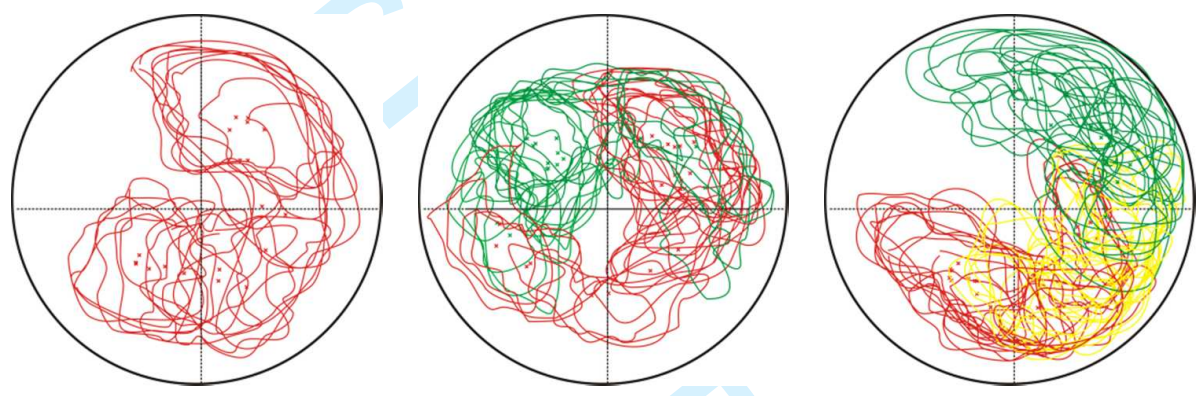

(d) 1-piece specimen, 648rpm; (e) 2-piece specimen, 648rpm; (f) 3-piece specimen, 648rpm

Figure 3. Fabric movement with different washing loads

Figures 3(a)-3(c) represent fabric movement during the washing procedure with a 389rpm rotating speed and a washing load of one-piece, two-piece and three-piece specimens, respectively. Comparing the red specimen in different loading conditions, it is clear that as the number of specimens increases, the distance and speed of the fabric movement decrease. This phenomenon could be explained by the fact that the mechanical action imposed on fabric that leads to wrinkling consists of hydrodynamic and compressional forces from inner drum and other textiles. Figures 3(d)-3(f) show movements at the rotating speed of 648rpm, and the trends of fabric movement in distance and speed are the same as those in Figures 3(a)-3(c).We also tested the smoothness of woven cotton fabric with different washing loads as well as the output energy of motor (as shown in Figure 4). The specimens used to evaluate the smoothness were C6 (as shown in Table 4). 


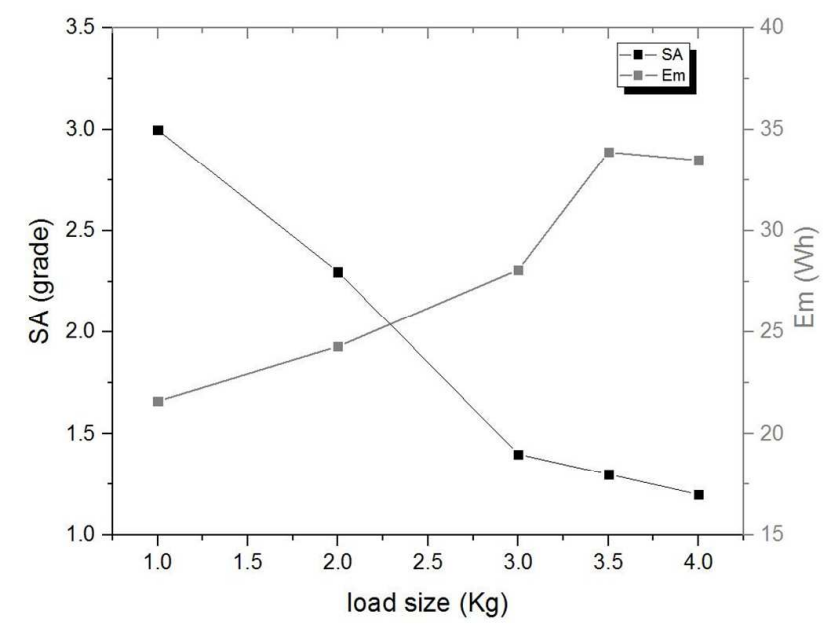

Figure 4. Smoothness appearance with washing loads from $1 \mathrm{~kg}$ to $4 \mathrm{~kg}$ at rotating speed of 389

$$
\text { rpm }
$$

According to Figure 4, we can conclude that with increasing washing load, fabric smoothness decreases, and fabric wrinkles more easily. However, when the washing load is above $3.5 \mathrm{~kg}$ ( $7 \mathrm{~kg}$ washing capacity), the smoothness grades begin to flatten around grade 1 . This happens because there is not enough space for fabrics to spread when the wash load is over $3.5 \mathrm{Kg}$. It is possible that compressional forces from inner drum and other fabrics is the main reason for wrinkling. It indicates 1) a $50 \%$ washing load is enough for woven cotton fabrics to wrinkle severely; and 2) the electric energy consumption $\left(E_{m}\right)$ is negatively related to smoothness as shown in Figure 4. Here, electric energy is introduced because it is the energy source of the fabric movement. It is assumed that the frictional losses in the bearings are negligible and thus the output motor power is completely dissipated on water and wet textiles during washing. The electric energy is directly related to fabric movement. Since knowing the fabric's speed is difficult, the electric energy consumption of a washing cycle $\left(\mathrm{E}_{\mathrm{w}}\right)$ could be used instead.

\section{The relationship between rotating speed, fabric movement and wrinkling}

After determining the relationship between the washing load and wrinkling, we analyzed the effects of the rotating speed on the smoothness as well. Similarly, we investigated the movements for one piece of specimen with the rotating speed changing from $259 \mathrm{rpm}$ to $1036 \mathrm{rpm}$ (Figure 6). All washing procedures were common and kept as much the same as possible apart from the rotating speed, as shown in Table 3. The specimens used to evaluate the smoothness were C6 (as 
shown in Table 4).

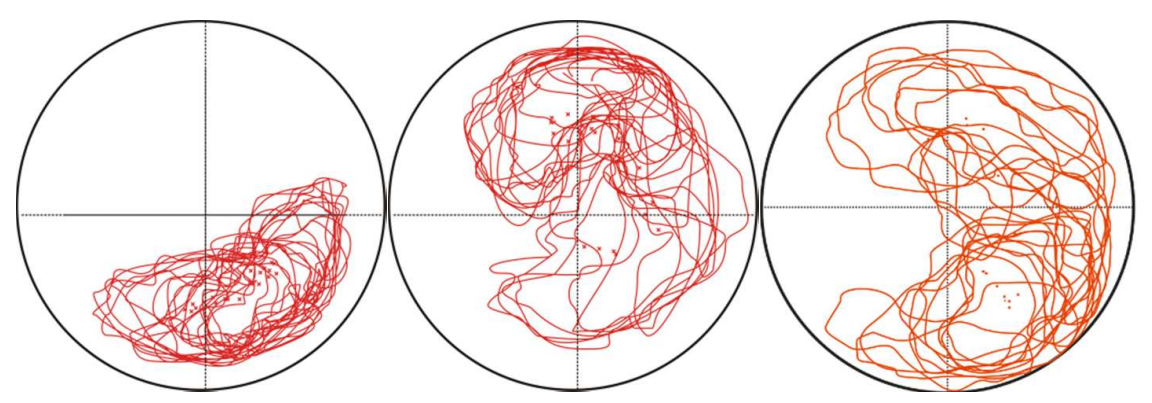
(a) $259 \mathrm{rpm}$
(b) $389 \mathrm{rpm}$
(c) $518 \mathrm{rpm}$

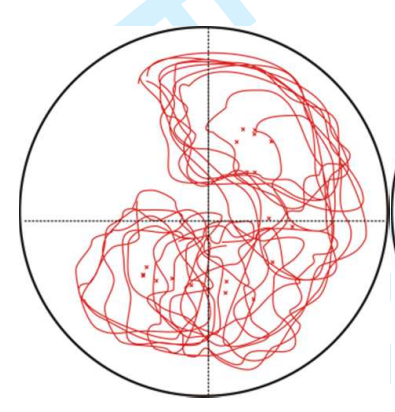

(d) $648 \mathrm{rpm}$

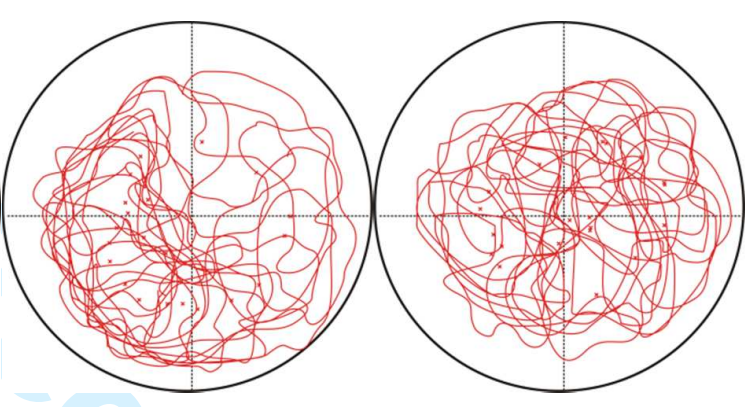

(e) $777 \mathrm{rpm}$

(f) $907 \mathrm{rpm}$

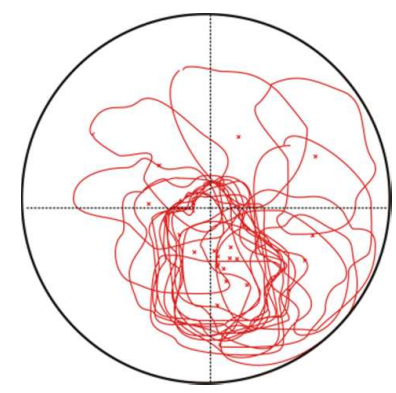

(g) 1036rpm

Figure 5. Fabric movement with different rotating speeds

Figures 5(a)-5(g) represent fabric movements with rotating speed changing from 259rpm to 1036rpm. We can make the following obvious conclusions: 1) the higher the rotating speed, the longer the distance the fabric moves; 2) when the rotating speed is $259 \mathrm{rpm}$, the fabric is almost static. This occurs because the force imposed on the fabric is smaller than it is when the rotating speed is higher. This phenomenon can be explained by the fact that when the drum rotation is faster, the hydrodynamics imposed on the fabric is stronger. To analyze the relationship between fabric movement and wrinkling, we tested the smoothness of woven cotton fabrics with different rotating speeds as well as the output energy of washer motor (as shown in Figure 6). 


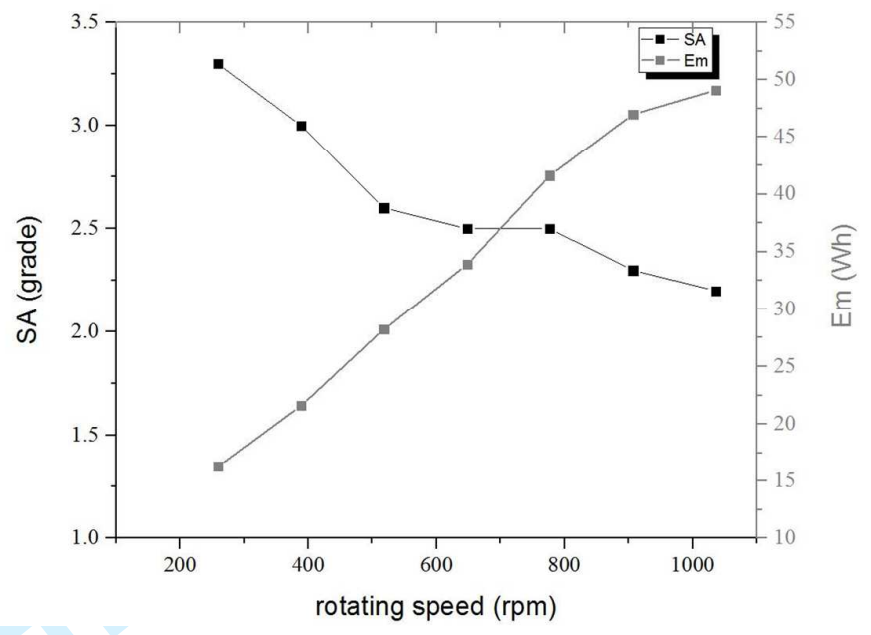

Figure 6. Smoothness appearance with rotating speed from 259rpm to 1036rpm

Figure 6 indicates the following: 1) a faster rotating speed with a higher electricity energy consumption tends to have a lower smoothness grade after washing; 2) the smoothness begins to flatten around grade 2 when the rotating speed is above $907 \mathrm{rpm}$ under the premise that the washing load is kept low (less than $50 \mathrm{~g}$, weight of one piece of fabric). As shown in Figure 4, when the washing load increases from $1.0 \mathrm{~kg}$ to $4.0 \mathrm{~kg}$, the smoothness decreases from grade 3.0 to grade 1.2 at the rotating speed of $389 \mathrm{rpm}$. The $\mathrm{p}$ value of washing load and rotating speed is 0.000 and 0.036 respectively through the anaylsis of variance. We can conclude that the wrinkling performance is affected more by the washing load than by the rotating speed. Moreover, the electric energy is also positively related to rotating speed as shown in Figure 6, and we can use the electric energy consumption of a washing cycle $\left(E_{m}\right)$ as an indicative parameter, as before.

\section{Correlation between fabric movement and smoothness}

We have conducted a curvilinear regression analysis to test the assumption that fabric movement during washing is influenced by the washing parameters, and consequently, fabric movement would determine the wrinkling of the fabric. Moreover, it is also assumed that a) the frictional losses are negligible, b) the fluid and cloth velocities are equal. 


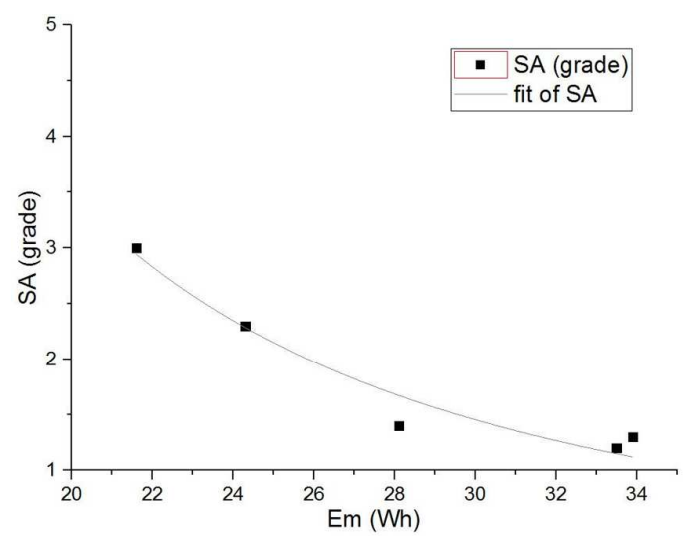

Figure 7. Nonlinear curve fit between smoothness appearance and $\mathrm{E}_{\mathrm{m}}$ (with changing load size)

Figure 7 shows the relationship between smoothness and electric energy consumption during a washing cycle. From Figure 7, we can see that the greater the energy the motor consumes, the lower the smoothness grade is. This can explain the fact that increasing washing load needs more energy to keep fabrics and water moving under the same rotational speed. Since getting the quantitative data of washing movement is difficult, we introduce electric energy consumption of a washing cycle $\left(E_{m}\right)$ as an indicative parameter. Table 6 shows the model coefficients for smoothness and fabric movement under the influence of washing load.

Table 6. Parameters of nonlinear curve fit with different washing loads

\begin{tabular}{|c|c|c|c|c|c|}
\hline & \multicolumn{2}{|c|}{ Unstandardized } & \multirow[b]{2}{*}{ Standardized Coefficient } & \multirow[b]{3}{*}{$\mathrm{t}$} & \multirow[b]{3}{*}{ Sig. } \\
\hline & \multicolumn{2}{|c|}{ Coefficients } & & & \\
\hline & B & SE & Beta & & \\
\hline $1 / \mathrm{E}_{\mathrm{m}}$ & 101.527 & 15.102 & 0.968 & 6.723 & 0.007 \\
\hline ( constant) & -1.869 & 0.560 & - & -3.341 & 0.044 \\
\hline
\end{tabular}

Note: dependent variable is SA

Substituting the unstandardized coefficients B into the inverse function model, we have Eq. (1) as follows:

$\mathrm{SA}=-1.869+\frac{101.527}{E_{m}}=-1.869+\frac{101.527}{E_{f}+E_{w}}=-1.869+\frac{203.54}{m_{w} v^{2}+m_{f} v^{2}}$

Where,

SA- Smoothness grade;

$E_{m}$ - Electric energy consumption of a washing cycle, Wh; 
$\mathrm{E}_{\mathrm{f}}-\frac{m_{f} v^{2}}{2}$,Energy consumption of fabric movements, Wh;

$\mathrm{E}_{\mathrm{W}} \frac{m_{w} v^{2}}{2}$, Energy consumption of the motion of water, Wh;

$\mathrm{k}-\mathrm{E}_{\mathrm{f}} / \mathrm{E}_{\mathrm{w}}$;

$m_{w}$ - Mass of water excluding water absorbed by fabrics, $\mathrm{kg}$;

$m_{f}$ - Mass of wet textiles, $\mathrm{kg}$;

$\mathrm{v}$ - velocity of textile and water, $\mathrm{m} / \mathrm{s}$.

The water volume for the washing procedure is $V_{\text {water }}(L)$. However, different washing machines and washing procedures have different washing capacities and water volumes, these two factors would act together to impact washing space and garment wrinkling. Therefore, we defined a dimensionless parameter liquor ratio to describe the synergistic effect:

$$
\mathrm{f}=\frac{m_{f}}{m_{w}}
$$

Substituting Eq. (2) into Eq. (1), we can obtain the relationship between smoothness and liquor ratio $f$ as follows:

$$
\mathrm{SA}=-1.869+\frac{203.54 f}{(1+f) m_{f} v^{2}}
$$

Eq. (3) shows a negative correlation between smoothness and washing load which indicts that the higher the washing load is, the lower the fabric smoothness will be under the same liquor ratio constant. Washing procedures with greater washing loads will generally lead to higher liquor ratio with a constant water volume; moreover, higher liquor ratio makes fabric more likely to bend or deform under the stress from the cylinder wall and other fabrics in the inner drum. Wrinkling can be reduced by lowering the "liquor ratio" through methods such as reducing washing load, increasing water volume etc. 
Table 7. Parameters of nonlinear curve fit with changing of rotating speed

\begin{tabular}{cccccc}
\hline \multicolumn{7}{c}{ Unstandardized } & & & \\
& \multicolumn{2}{c}{ Coefficients } & Standardized Coefficient & & \\
& $\mathrm{B}$ & $\mathrm{SE}$ & $\mathrm{Beta}$ & $\mathrm{t}$ & Sig. \\
\hline $1 / \mathrm{Em}$ & 24.360 & 1.633 & 0.989 & 14.916 & 0.000 \\
(constant) & 1.795 & 0.060 & & 29.868 & 0.000 \\
\hline
\end{tabular}

Note: the dependent variable is SA

Substituting the unstandardized coefficient B into the inverse function model, we obtain Eq. (4) as follows: 


$$
\mathrm{S}=1.795+\frac{24.36}{\mathrm{E}_{\mathrm{m}}}=1.795+\frac{24.36}{\mathrm{E}_{\mathrm{m}}+\mathrm{E}_{\mathrm{w}}}=1.795+\frac{48.72}{\mathrm{~m}_{\mathrm{f}} v^{2}+\mathrm{m}_{\mathrm{w}} v^{2}}
$$

In this research, we assumed that the fabric was conducting an ideal centrifugal motion during the minimum washing period which is about 3 seconds in a top-loading washing machine. Therefore, the formulations of force on the fabric was reduced to centrifugal force $F_{c e n}$. The calculating formula is as follows:

$$
\mathrm{F}_{\mathrm{cen}}=\frac{m_{f} v^{2}}{r}=\frac{2 m_{f} v^{2}}{R}
$$

Where

$\mathrm{r}$ - movement radius of fabric, $\mathrm{m}$; and

$\mathrm{R}$ - radius of the inner drum of the top loading washer, $\mathrm{m}$.

Substituting Eq. (2) and (5) into Eq. (4), we obtain the relationship between smoothness and "centrifugal force $\mathrm{F}_{\text {cen }}$ " as follows:

$$
\mathrm{SA}=1.795+\frac{97.44 f}{(1+f) F_{c e n} R}
$$

Eq. (6) shows a negative correlation between smoothness and "centrifugal force $\mathrm{F}_{\text {cen." }}$ "This can explain the fact that the higher the rotating speed is, the lower the fabric smoothness will be under the same liquor ratio. Washing procedures with higher rotating speeds will generally lead to a stronger centrifugal force; a stronger centrifugal force makes fabric deform more severely. Wrinkling may be decreases by reducing the centrifugal force through methods such as slowing down the rotating speed.

\section{Conclusions}

We have found that the major washing parameters that affect the fabric movements and wrinkling are washing load and rotating speed. The analysis of fabric movements during washing has indicated that the higher the washing load is, the larger the liquor ratio will be, and the more readily the fabrics would interact with other textiles and the drum and thus the fabrics will bend and deform more. Additionally, higher rotating speeds lead to stronger forces on the fabric and thus cause more wrinkles. We have developed regression models showing the relationships between fabric smoothness, the liquor ratio and centrifugal force.

The findings provide fundamental information that can be used to develop an appropriate washing program for a top-loading washer that leads to improved fabric smoothness after washing 
through such methods as reducing washing load size and rotating speed. Further investigation of the effects of washing parameters on the washing appearance of garments made of other materials, such as silk and wool, will be carried out to build a system dedicated to the easy care of garments.

\section{Acknowledgements}

The authors would like to thank the National Natural Science Foundation of China for providing funding support to this research through project 71373041, and Donghua University for providing funding support to this research through project "the Fundamental Research Funds for the Central Universities", and Haier Group for providing facilities and technology support to this study.

\section{References}

1. Marie T. Schlag and Ordoñez M. Comparison of the effect of a top-loading and a frontloading washing machine on cotton fabrics. Proceedings of the Annual International Conference \& Exhibition of AATCC. 2010: 30-40.

2. Zhang M, Wang S, Wang C and Li J. A facile method to fabricate superhydrophobic cotton fabrics. Applied Surface Science. 2012; 261: 561-6.

3. Široká B, Manian AP, Noisternig MF, et al. Wash-dry cycle induced changes in low $\square$ ordered parts of regenerated cellulosic fibers. Journal of Applied Polymer Science. 2012; 126.

4. Higgins L, Anand S, Holmes D, Hall M and Underly K. Effects of various home laundering practices on the dimensional stability, wrinkling, and other properties of plain woven cotton fabrics part II: effect of rinse cycle softener and drying method and of tumble sheet softener and tumble drying time. Textile research journal. 2003; 73: 407-20.

5. Park S, Yun C, Kim J and Park CH. The effects of the fabric properties on fabric movement and the prediction of the fabric movements in a front-loading washer. Textile Research Journal. 2013; 83: 1201-12.

6. Gocek I, Sahin UK, Erdem I, Namal O and Acikgoz H. A study on easy-care laundering of linen fabrics. Textile Research Journal. 2013; 83: 1961-73. 
7. Jianrong Y, Zhaojun L, Juan H and Xuemei D. Effect of dewatering speed on surface properties of cotton shirts during domestic tumble laundering. China Fiber Inspection. 2013: 79-81.

8. Yuan J, Li Z, Hu J and Ding X. Effect of Dewatering speed on surface properties of cotton shirt during domestic tumble taundering. Inspection \& Sicence. 2013: 79-81.

9. Yuan J, Li Z, Wu X and Ding X. Effect of washing temperature on smoothness appearance of woven fabrics during domestic tumble laundering. Journal of Textile Research. 2014: 74-8.

10. Mac Namara C, Gabriele A, Amador C and Bakalis S. Dynamics of textile motion in a front-loading domestic washing machine. Chemical Engineering Science. 2012; 75: 14-27.

11. Yun C, Park S and Park $\mathrm{CH}$. The effect of fabric movement on washing performance in a front-loading washer. Textile Research Journal. 2013: 0040517512452927.

12. Balt A, van den Brekel L, Vandecasteele C and Kolar Z. Radiotracer study of wash load movement in a drum-type fabric washing machine using a gamma camera. International Journal of Radiation Applications and Instrumentation Part A Applied Radiation and Isotopes. 1987; 38: $7-12$.

13. Yun $\mathrm{C}$ and Park $\mathrm{CH}$. The effect of fabric movement on washing performance in a front-loading washer III: Focus on the optimized movement algorithm. Textile Research Journal. 2015: 0040517515590417.

14. Wang L, Liu JL, Pan RR and Gao WD. Dynamic measurement of fabric wrinkle recovery angle by video sequence processing. Textile Research Journal. 2014; 84: 694-703.

15. Yuan J, Sun F and Ding X. Mechanism and influencing factors of woven fabric wrinkling during domestic tumble laundering. China Appliance Technology. 2013: 64-7.

16. Commission IE. IEC 60456: Clothes washing machines for household use-methods for measuring the performance. 2009.

17. AATCC. Smoothness apperance of fabrics after repeated home laundering. 2009.

18. Akcabay DT, Dowling DR and Schultz WW. Clothes washing simulations. Computers \& Fluids. 2014; 100: 79-94. 


\section{Response to reviews}

\section{Reviewer1:}

1. Page 1, line 39 (Abstract): Do you mean liquor ratio instead of washing space?

Reply: the term has been replaced by liquor ratio.

Before: The smoothness grade increased with the decrease of washing load and drum rotating speed since these settings led to more washing space and less stress on the fabric.

After: The smoothness grade increased with the decrease of washing load and drum rotating speed since these settings led to lower liquor ratio with a constant water volume and less stress on the fabric.

2.Page 13, lines 29-33: Please, read the sentence once more and correct it properly. (Notes: From Figure $4 \mathrm{I}$ can only see that the value of SA decreases from 3 to approximately 1.2 when the washing load increases from 1 to $4 \mathrm{~kg}$. From Figure $4 \mathrm{I}$ cannot see that the value of SA decreases from 3.3 to 2.2. (these results are presented in Figure 6).

Reply: I have corrected them in the manuscript. As shown in Figure 4, when the washing load increases from $1.0 \mathrm{~kg}$ to $4.0 \mathrm{~kg}$, the smoothness decreases from grade 3.0 to grade 1.2 at the rotating speed of $389 \mathrm{rpm}$. 